\title{
Tracking Accuracy of Large and Small-CAP ETFS: an Empirical Analysis of The Istanbul Stock Exchange
}

M. Mesut Kayali, Seyfettin Unal*

Abstract:

In this study, we examine the tracking performance of two ETFs, namely DJIST and SMIST, both traded on the Istanbul Stock Exchange, with respect to their own indices. We carry out an analysis first to identify each ETF's tracking ability of underlying index, and second to explore whether any differences exist between the return of large-cap and the return of small-cap stock ETFs, and their indices. By employing a data set of calculated daily returns for the specified ETFs and their corresponding indices, $t$-tests and regression analyses are conducted. Our findings suggest that both DJIST and SMIST stocks performed well in tracking their own indices' returns. However, the mimicking ability of DJIST stock is better than that of SMIST. Possible explanations regarding this difference are that the SMIST's introduction into the market is relatively new compared to the DJIST, and that the SMIST represents small-cap stocks with considerable illiquidity problems, while the DJIST represents large-cap stocks. Despite the odds, against the SMIST, it still shows a tracking performance that should be acknowledged, given both its place in an emerging market and its strength within such a short period of time.

Keywords: Exchange Traded Funds, Tracking Accuracy, Dow Jones Istanbul 20, Turkish Smaller Companies Istanbul 25.

JEL: G12, G15.

DOI: $10.2478 / v 10033-009-0007-2$

\section{Introduction}

The basic premise of Exchange Traded Funds (ETFs) is to deliver returns in line with their target benchmarks. The most common way of evaluating their performance is to determine how closely their return tracked the return of their underlying indices. The smaller the differences between the returns of ETFs and their corresponding indices, the more successful the ETFs are in mirroring the performance of their benchmarks.

The tracking performance of ETFs depends upon their liquidity. The returns of relatively new and illiquid ETFs, tracking indices including small-cap or emerging market stocks, may depart from the returns of their underlying benchmarks. However, their tracking performance may proliferate over time as investor interest grows sufficiently.

This paper investigates the tracking abilities of the two ETFs listed on the Istanbul Stock Exchange (ISE).
One of them is the Dow Jones Istanbul 20, the first ETF in Turkey when it was introduced in 2005. The other is the Turkish Smaller Companies Istanbul 25, the first

\section{* Mesut Kayali}

Dumlupinar University, Faculty of Economics and Administrative Sciences

Department of Business Administration, Kutahya,

Turkey.

E-mail: mesutkayali@yahoo.com

\section{Seyfettin Unal}

Dumlupinar University, Faculty of Economics and Administrative Sciences, Department of Business Administration, Kutahya, Turkey

Dumlupinar Universitesi IIBF

E-mail: sunal@dumlupinar.edu.tr 
style ETF traded on the ISE since August 24, 2006. Although there are several ETFs traded on the Turkish market, our study focuses on only these two, based on their unique comparable features of being large-cap and small-cap. We compare the daily returns of those ETFs with the daily returns of their underlying indices, take the differences and average them out. We test the null hypothesis that the differences between returns are zero. As a result, we find that the average daily returns are not statistically and significantly different from each other. Also, we perform a regression of returns for each ETF and find that the DJIST tracks its benchmark better than the SMIST does.

This paper is organized as follows: the next section provides a brief review of the related literature, the third section describes the data and the methodology, the fourth section comments on the empirical results, and the last section concludes the paper.

\section{Brief Review of the Related Literature}

Khorana et al. (1998) examine the extent to which WEBS returns track the return on the underlying $\mathrm{MSCl}$ index. They provide the first evidence on the performance of WEBS. They find that over the sixmonth period following their introduction, WEBS returns closely track the underlying $\mathrm{MSCl}$ country index.

Patro (2001) provides empirical evidence that the WEBS have been successful in matching the performances of the market indexes they represent. They cannot reject the null hypothesis that the difference between the WEBS returns and the corresponding $\mathrm{MSCl}$ market index returns is zero for all seventeen WEBS at the 1 percent level.

Pennathur et al. (2002) study the performance of iShares from April 1996 to December 1999. They extend the work of Khorana et al. (1998). Their singleindex model demonstrates that iShares replicate the home index.

Conducting a comparative performance analysis of ETFs and index funds with respect to their benchmark indices, Rompotis (2005) reports no excess return is produced by ETFs and index funds over their benchmark indices. The study also reveals an analogous tracking ability of ETFs and index funds based on the computation of their average tracking errors.

Kuo and Mateus (2006) perform an analysis on the performance and persistence of 20 iShares $\mathrm{MSCl}$ country-specific exchange-traded funds (ETFs) in comparison with the S\&P 500 index. They provide evidence that ETFs can beat the U.S. market index based on risk-adjusted performance measures. They also conclude that past performance of iShares $\mathrm{MSCl}$ country-specific ETFs can predict future performance, suggesting that investors could use past annual return for selecting iShares $\mathrm{MSCl}$ country-specific ETFs to predict future annual returns.

Harper et al. (2006) compare the returns of international ETFs with the returns of their underlying market indices over the sample period from April 1996 to December 2001. They contribute to the existing literature on ETFs by verifying the high tracking accuracy of the ETFs to the underlying indices.

Iseri and Aktas (2006) evaluated the tracking performance of the DJIST during 2005. They compare the percentage changes between the beginning value and ending value of the DJIST and the DJTT20 index. They also show the trend in both price series graphically and conclude that the DJIST and the underlying index move in tandem.

Kayali (2007a) analyzes the difference between the closing price of the DJIST and the net asset value of the underlying portfolio in terms of New Turkish Lira (TRY) for the first year of its trading. He finds that the average TRY difference is statistically significant but not significant economically. Also, he provides empirical evidence that deviations of prices from NAV do not persist over time and vanish on the second day of their occurrence.

Kayali (2007b) tests the investor sentiment hypothesis well-known in the closed-end fund literature by using the percentage premiums and discounts of the DJIST in 2005. He looks into their behavior in up and down markets. He finds that the DJIST trades at discounts in both market conditions, the discount being larger in rising markets. This finding contradicts the investor sentiment theory.

Kayali (2007c) studies the mispricing issue of the DJIST during 2005. As a result, he finds that the DJIST is statistically mispriced on average but not to the extent that arbitrage is granted frequently. Also, the percentage deviations of prices from NAV do not behave differently in high and low volatile underlying markets for at least the first year.

\section{Data and Methodology}

In the study, we conduct the analysis on daily returns of indices and ETFs for the DJIST 20 and the SMIST 25. The returns are calculated by using daily closing index values of the DJIST 20 and the SMIST 25. Index data are obtained from their original Internet websites (www.djist.com and www.smist.com) for overlapping time periods, starting on August 24, 2006, which is the date the SMIST's ETF began trading on the Istanbul 
Stock Exchange (ISE), and ending on August 31, 2007. The period covers the data of 254 trading days. Within the covered period, four days are omitted due to missing unreachable data values. Yet the data still cover one year of trading days. Daily closing stock price data for DJIST and SMIST are collected from CNNTurk's website (www.cnnturk.com). In order to verify the reliance of stock price data set, several randomlyselected data are also cross checked with daily closing prices announced on the ISE website. Stock price data also cover the same period between 8-24-2006 and 831-2007. A recent picture of DJIST and SMIST, regarding their market data and industrial breakdown is reflected in Table 1.

The return series used in the empirical analysis are computed as follows:

$$
r_{t}=\left[\left(p_{t}-p_{t-1}\right) / p_{t-1}\right]^{*} 100,
$$

where $r_{t}$ is the return on day $t$ and $p_{t}$ and $p_{t-1}$ are the closing prices of the ETFs, or the levels of the corresponding indices, on days $t$ and $t-1$.

In order to assure the tracking accuracy of ETFs, we run two regressions of daily returns on each ETF against their corresponding returns on the indices. Below is the empirical computations employed:

$$
\begin{aligned}
& r_{d s, t}=\alpha_{d s}+\beta_{d s} r_{d x, t}+e_{d s, t} \\
& r_{s s, t}=\alpha_{s s}+\beta_{s s} r_{s x, t}+e_{s s, t}
\end{aligned}
$$

where $r_{d s, t}$ and $r_{s s, t}$ are the returns on ETF stock of DJIST and SMIST, respectively, on day $\mathrm{t}$, and $r_{d x, t}$ and $r_{s x, t}$ are the returns on the DJIST and SMIST indices, respectively, on day $t$. The statistical analysis is performed on the SPSS.

\section{Empirical Findings}

\subsection{Summary Statistics and t-Tests}

As shown in Table 2, the total one-year holding period returns for the DJIST index and ETF are $36.27 \%$ and $43.23 \%$, respectively, while corresponding returns for the SMIST index and ETF are $36.31 \%$ and $35.03 \%$, respectively. In terms of daily return performances, reflected in Table 3, the daily mean returns for the DJIST index and ETF are both positive and fall between $0.1375 \%$ and $0.1571 \%$, and those for the SMIST are also positive and remain between $0.1350 \%$ and 0.1320 . With respect to the highest and lowest levels, daily returns hit as high as $5.2820 \%$ and fall as low as $6.4858 \%$ for the DJIST index and ETF. On the other

\begin{tabular}{|c|c|c|c|}
\hline \multicolumn{2}{|l|}{ DJIST } & \multicolumn{2}{|l|}{ SMIST } \\
\hline Market capitalization & $\$ 55.7 \mathrm{M}$ & Market capitalization & $\$ 0.9 \mathrm{M}$ \\
\hline Average daily trading volume & $\$ 10.7 \mathrm{M}$ & Average daily trading volume & $\$ 1.2 \mathrm{M}$ \\
\hline Sector breakdown & & Sector breakdown & \\
\hline Banking & $45.14 \%$ & Oil, Gas \& Petrochemical & $18.55 \%$ \\
\hline Conglomerates & $14.61 \%$ & Transportation & $11.16 \%$ \\
\hline Petroleum & $10.17 \%$ & Banking & $10.97 \%$ \\
\hline Telecom & $9.23 \%$ & Construction & $9.75 \%$ \\
\hline Steel \& Metal & $7.81 \%$ & Media & $7.85 \%$ \\
\hline Food \& Beverage & $4.53 \%$ & Insurance & $6.88 \%$ \\
\hline Retail & $3.61 \%$ & Automotive & $6.26 \%$ \\
\hline Others & $4.87 \%$ & Logistics & $6.09 \%$ \\
\hline \multirow{4}{*}{ *As of August 31, 2007} & & Food \& Beverage & $4.79 \%$ \\
\hline & & Consumer durables & $4.59 \%$ \\
\hline & & Conglomerates & $3.76 \%$ \\
\hline & & Others & $9.36 \%$ \\
\hline
\end{tabular}
hand, the highest and lowest daily returns for the SMIST index and ETF are $5.7613 \%$ and $-7.0539 \%$,

Table 1: Recent market data and characteristics of DJIST and SMIST*

Source: www.djist.com and www.smist.com 


\begin{tabular}{|l|c|c|c|c|}
\hline \multirow{2}{*}{} & \multicolumn{2}{|c|}{ DJIST } & \multicolumn{2}{c|}{ SMIST } \\
\cline { 2 - 5 } & Index & ETF & Index & ETF \\
\hline Number of trading days & 254 & 254 & 254 & 254 \\
\hline Minimum & 353.28 & 9.24 & 249.05 & 8.96 \\
\hline Maximum & 548.54 & 15.05 & 379.99 & 13.75 \\
\hline Beginning value (8/24/2006) & 362.06 & 9.46 & 253.78 & 9.22 \\
\hline Ending value (8/31/2007) & 493.38 & 13.55 & 345.92 & 12.45 \\
\hline Percentage change & 36.27 & 43.23 & 36.31 & 35.03 \\
\hline
\end{tabular}

Table 2: Summary Statistics

\begin{tabular}{|l|c|c|c|c}
\hline \multirow{2}{*}{} & \multicolumn{2}{|c|}{ DJIST } & \multicolumn{2}{c}{ SMIST } \\
\cline { 2 - 5 } & Index return & ETF return & Index return & ETF return \\
\hline Minimum & -6.4858 & -6.2745 & -6.3440 & -7.0539 \\
\hline Range & 5.2820 & 5.2448 & 4.6940 & 5.7613 \\
\hline Mean & 11.7677 & 11.5193 & 11.0380 & 12.8153 \\
\hline Standard deviation & 0.1375 & 0.1571 & 0.1350 & 0.1320 \\
\hline t-statistics & 1.7386 & 1.7349 & 1.6404 & 1.7302 \\
\hline p-value & \multicolumn{2}{|c}{0.587} & \multicolumn{2}{c}{0.055} \\
\hline
\end{tabular}

Table 3: Daily Returns (\%)

respectively.

Keeping in mind the ups and downs in Turkish politics, especially between April and August 2007, these highest and lowest points should be considered understandable, even moderate. Moreover, Table 3 provides the results of a $t$-test that suggests that mean return differences of the DJIST are not statistically different from zero at the $1 \%$ level with a t-value of 0.587 and a p-value of 0.558 . Similarly, the test results for the SMIST also verify that at the $1 \%$ level, differences in mean returns of the SMIST are statistically insignificant, with a t-value of 0.055 and a p-value of 0.956 . Table 3 also reports the standard deviations in the index and ETF returns of the DJIST and the SMIST. As can be seen, these data also reflect the close relationship of ETFs with their underlying indices, thus implying their high tracking abilities. In addition, the Figures 1 and 2 are drawn to reflect the tracking performances of the DJIST and the SMIST stocks. Figure 1 shows the DJIST stock's relative return performance with its underlying index, as DXRET and DPRET refer to index return and stock return, respectively. In Figure 2, the SMIST stock's relative return performance with its underlying index is drawn, as SXRET and SPRET refer to index return and stock return, respectively.

\subsection{Results of Return Regressions}

The results of regression equations are summarized in Table 4. The analysis provides the estimates of coefficient, t-statistics and $p$-value for DJIST and SMIST. By examining the R-squares of regression equations, we attempt to determine the ETF stocks' mimicking performance of underlying indices. In this respect, a higher R-square means higher tracking accuracy (or lower tracking error). A higher tracking accuracy (or lower tracking error) is an indication that ETF stock return closely imitates the return pattern of the underlying index. 


\begin{tabular}{|l|c|c|c|c|c|c|}
\hline & \multicolumn{3}{|c|}{ DJIST } & & \multicolumn{3}{c|}{ SMIST } \\
\cline { 2 - 7 } & Constant & Beta & R-square & Constant & Beta & R-square \\
\hline Coefficient & 0.02639 & $0.953^{* *}$ & 0.908 & 0.008412 & $0.868^{* *}$ & 0.753 \\
\hline t-statistics & 0.795 & 49.840 & & 0.155 & 27.685 & 0.000 \\
\hline p-value & 0.428 & 0.000 & & 0.877 & 0 \\
\hline
\end{tabular}

** Statistically significant at the $1 \%$ level.

Table 4: Regression analysis between index returns and ETF returns

According to the regression outcomes, we find a $90.8 \%$ of R-square for the DJIST equation, implying that ETF stock return quite accurately mimics the return on its corresponding index. Even though being fairly lower than that of the DJIST, an R-square of $75.3 \%$ for the SMIST demonstrates that its stock return also accurately imitates the return on the underlying index. This fair difference between the two stocks' R-square estimates is not contrary to expectations. First, we carry out the study by using the data set that begins with the first day when SMIST stock started trading. Since SMIST stock is considerably new and started trading about 19 months later than DJIST stock, it may require some period of time in the market to accustom to SMIST stock. Second, this distinction may be attributable to market capitalization impact. This is because the securities represent two groups of stock indices with differing market capitalizations, large-cap and smallcap. This realized difference is also highlighted by standard deviations in Table 3. There is only a slight difference in the DJIST's standard deviations of returns, 1.7386 versus 1.7349 , whereas the same values for the SMIST are 1.6404 and 1.7302. Overall, the analyses confirm that both ETF stocks of the DJIST and the SMIST accurately follow their corresponding underlying indices, although DJIST stock mimics its index better than SMIST stock.

\section{Concluding Remarks}

In this study, we attempt to analyze the tracking performance of two ETFs on their underlying indices. In order to reveal whether any differences exist with respect to their mimicking performance, we choose to compare DJIST stock to SMIST stock. Using a one-year data set, consisting of 254 trading days, our purpose is to demonstrate similarities or differences, if any, in the tracking abilities of these two stocks in an emerging market.

In the hope that our study opens a new path for further research on ETFs in Turkey, we also remind that the paper is the first, to the best of our knowledge, to identify the tracking ability of ETFs with two different features. That is, the DJIST follows an index representative of large capitalization stocks. On the other hand, the SMIST represents another index that consists of small capitalization stocks.

By employing first a $t$-test and then a regression of daily returns of each stock on their underlying indices, we reach two conclusions. First, both stocks accurately track their underlying indices. Second, DJIST stock's tracking performance is fairly better than that of SMIST. Considering that the SMIST is relatively new compared to the DJIST, and that our data set starts with the first day of the SMIST's introduction, this result is quite understandable. Moreover, the SMIST is representative of small-cap stocks, whereas the DJIST is representative of large-cap stocks. Despite the fact that the SMIST is relatively new, this performance is unexpectedly strong. A possible explanation for this lies in its portfolio component. Compared to the heavy weight of the banking sector in the DJIST, the banking sector constitutes only about $11 \%$ of the SMIST portfolio. In addition, with respect to the number of industries covered, the SMIST reflects a more diversified portfolio. This implies that the SMIST or future the SMIST-like ETFs may be expected to open a new path for more diversified portfolio alternatives for investors. As a result, the study introduces preliminary evidence for the literature on ETFs in an emerging market by looking at the subject from another angle. ㅁ. 


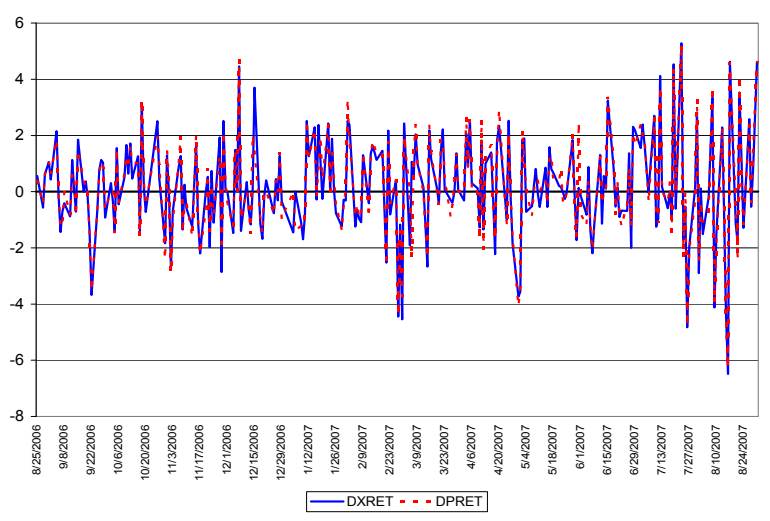

Figure 1

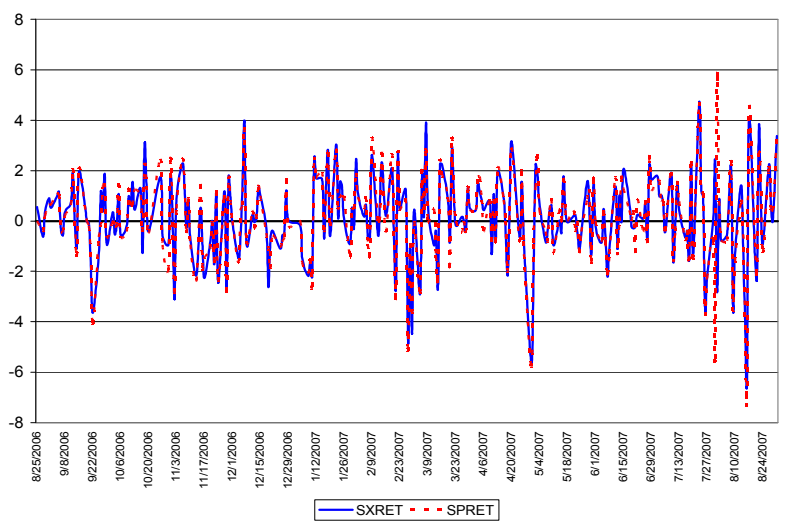

Figure 2

\section{References}

Harper, J.T., J. Madura and O. Schnusenberg. 2006. Performance comparison between exchange-traded funds and closed-end country funds. Journal of International Financial Markets, Institutions and Money 16 (2): 104-122.

Iseri, M. and Z. Aktas. 2006. Ulkemizde yatirim araclari icinde yeni bir alternatif: Borsa yatirim fonlari. Finans-Politik ve Ekonomik Yorumlar 43 (502): 53-64.

Kayali, M.M. 2007a. Pricing efficiency of exchange traded funds in Turkey: Early evidence from the Dow Jones Istanbul 20. International Research Journal of Finance and Economics 10: 14-23.

Kayali, M.M. 2007b. Do Turkish Spiders confuse bulls and bears?: The case of Dow Jones Istanbul 20. Investment Management and Financial Innovations 4 (3): 72-79.

Kayali, M.M. 2007c. Mispricing in exchange traded funds and arbitrage opportunities: The case of Dow Jones Istanbul 20. Paper to be presented at the $11^{\text {th }}$ National Finance Symposium, Zonguldak, Turkey, October.

Khorana, A., E. Nelling and J.J. Trester. 1998. The emergence of country index funds. Journal of Portfolio Management 24 (4): 78-84.

Kuo, T.W. and C. Mateus. 2006. The Performance and Persistence of Exchange-Traded Funds: Evidence for iShares MSCl country-specific ETFs. European Financial Management Association 2007 Annual Meetings, June 27- 30, 2007, Vienna, Austria.

Patro, D.K. 2001. Market segmentation and international asset prices: Evidence from the listing of World Equity Benchmark Shares. Journal of Financial Research 24 (1): 83-98.

Pennathur, A.K., N. Delcoure and D. Anderson. 2002. Diversification benefits of iShares and closed-end country funds. Journal of Financial Research 25 (4): 541-557.

Rompotis, G. G. 2005. An Empirical Comparing Investigation on Exchange Traded Funds and Index Funds Performance. Working paper, SSRN_ID903110_code628063.

http://www.cnnturk.com (accessed through out August 2007).

http://www.djist.com (accessed August through September 2007).

http://www.imkb.gov.tr (accessed through out August 2007).

http://www.smist.com (accessed August through September 2007). 